\title{
(CON)TEXTUALIZAÇÃO DA POLÍTICA DE EDUCAÇÃO ESPECIAL EM UM MUNICÍPIO SUL-MATO-GROSSENSE
}

\author{
(CON)TEXTUALIZACIÓN DE LA POLÍTICA DE EDUCACIÓN ESPECIAL EN UNA \\ CIUDAD DE MATO GROSSO DO SUL
}
(CON)TEXTUALIZATION OF THE SPECIAL EDUCATION POLICY IN A MUNICIPALITY OF MATO GROSSO DO SUL

\author{
Camila da Silva Teixeira AGRELOS ${ }^{1}$ \\ Washington Cesar Shoiti NOZU ${ }^{2}$
}

RESUMO: Este artigo se propõe a compreender a construção da política de Educação Especial do município de Maracaju, Mato Grosso do Sul, focalizando aspectos de influências externas, de práticas locais de Atendimento Educacional Especializado (AEE) e de produção textual recente que normatiza o tema. Trata-se de um estudo descritivo-exploratório, operacionalizado por meio de análise documental da Resolução SEME n. 2/2017 e de entrevista semiestruturada com a representante da Educação Especial na Secretaria Municipal de Educação de Maracaju. A investigação apontou a necessidade de controle orçamentário como um dos fatores preponderantes para regulamentação do AEE. O serviço de apoio em sala de aula comum é ofertado tanto por professores especialistas, como por profissionais com escolaridade de nível médio. Entretanto, com o aumento da demanda de alunos com deficiência, atrelado à redução orçamentária, há o receio da gestão da rede de ensino municipal de que, num futuro próximo, a contratação de professores especialistas para o apoio pedagógico torne-se inviável.

PALAVRAS-CHAVE: Política educacional. Municipalização do ensino. Inclusão escolar.

RESUMEN: Este artículo tiene como objetivo comprender la construcción de la politica de Educación Especial de la ciudad de Maracaju, Mato Grosso do Sul, Brasil, centrándose en los aspectos de las influencias externas, de las prácticas locales de Atención Educativa Especializada (AEE) y de la reciente producción textual que regula el tema. Se trata de un estudio exploratorio descriptivo, operado a través del análisis documental de la Resolución SEME n. 2/2017 y de una entrevista semiestructurada con el representante de Educación Especial del Departamento de Educación de Maracaju. La investigación señaló la necesidad del control de presupuesto como uno de los factores preponderantes para la regulación de la AEE. El servicio de apoyo en clases ordinarias es ofrecido tanto por profesores especialistas como por profesionales con estudios secundarios. Sin embargo, con el aumento de la

\footnotetext{
${ }^{1}$ Universidade Federal da Grande Dourados (UFGD), Dourados - MS - Brasil. Mestranda no Programa de PósGraduação em Fronteiras e Direitos Humanos (PPGFDH). ORCID: https://orcid.org/0000-0002-4330-5117. Email: camilateixeira@ufgd.edu.br

${ }^{2}$ Universidade Federal da Grande Dourados (UFGD), Dourados - MS - Brasil. Professor Adjunto, Docente Permanente do Programa de Pós-Graduação em Educação (PPGEdu) e no Programa de Pós-Graduação em Fronteiras e Direitos Humanos (PPGFDH). Doutorado em Educação (UFGD). ORCID: https://orcid.org/00000003-1942-0390. E-mail: washingtonnozu@ufgd.edu.br
}

RIAEE - Revista Ibero-Americana de Estudos em Educação, Araraquara, v. 16, n. esp. 2, p. 1360-1376, maio 2021. e-ISSN: 1982-5587 
demanda de estudiantes con discapacidades, vinculado a la reducción del presupuesto, existe el temor por parte de la administración de la red escolar municipal de que en un futuro próximo la contratación de profesores especialistas para el apoyo pedagógico sea inviable.

PALABRAS CLAVE: Política educativa. Municipalización de la educación. Inclusión escolar.

ABSTRACT: This article aims to understand the construction of the Special Education policy in the municipality of Maracaju, Mato Grosso do Sul, focusing on aspects of external influences, local practices of Specialized Educational Service (SES) and recent textual production that nomatizes the theme. It is a descriptive-exploratory study, operationalized through documentary analysis of Resolution SEME n. 2/2017 and semi-structured interview with the Special Education representative at the Municipal Education Secretariat of Maracaju. The investigation pointed out the need for budgetary control as one of the main factors for the regulation of the SES. The support service in the ordinary classroom is offered both by specialist teachers and by professionals with secondary education. However, with the increase in demand of students with disabilities, linked to budget cuts, there is a fear of the management of the municipal education network that, in the near future, the hiring of specialist teachers for pedagogical support may become unfeasible.

KEYWORDS: Educational policy. Municipalization of teaching. School inclusion.

\section{Introdução}

Nos anos 1980, movimentos sociais reivindicavam uma política educacional descentralizada e participativa, especialmente considerando o passado brasileiro, então recente, de autoritarismo e centralização de poder (GARCIA, 2009). A década de 1990 foi marcada por uma política de reformas, com vistas a adequar o país para abertura do mercado doméstico ao capital internacional. Dentre essas reformas está o processo de municipalização da educação, impulsionado pela Constituição Federal de 1988 (CF/88), que define o município como ente federativo com autonomia para criar sua própria rede de ensino (BRASIL, 1988).

Entretanto, ao instituírem redes de ensino, os municípios também foram confrontados a promoverem meios para assegurar, dentre outras demandas, a inclusão escolar de estudantes com deficiência, transtornos globais do desenvolvimento e altas habilidades/superdotação considerados público-alvo da Educação Especial (PAEE) (GARCIA, 2010).

A Lei de Diretrizes e Bases da Educação Nacional de 1996 (LDB/96) não apenas incumbiu os municípios de "organizar, manter e desenvolver os órgãos e instituições oficiais dos seus sistemas de ensino", como também lhes atribuiu a responsabilidade de "baixar normas complementares para os seus sistemas" (BRASIL, 1996). 
No âmbito da Educação Especial, alguns municípios também têm formulado documentos político-normativos com vistas a disciplinar essa modalidade em suas redes de ensino (MARTINS, 2011). A demanda por regulamentação tem origem no fato de que os documentos oficiais que orientam a política nacional de Educação Especial por vezes são silentes, vagos ou incoerentes no tocante a aspectos da atuação dos serviços de Atendimento Educacional Especializado (AEE), deixando espaços para interpretação e (re)contextualização política pelos atores da prática. Ou, ainda, são formulados levando em conta um ideal escolar que não corresponde às realidades educacionais municipais, especialmente no contexto de um país continental, como o Brasil (MAINARDES, 2006; 2018).

Assim, o presente artigo se propõe a compreender a construção da política de Educação Especial do município de Maracaju, Mato Grosso do Sul (MS), focalizando aspectos de influências externas, de práticas locais de AEE e de produção textual recente que normatiza o tema.

Trata-se de um estudo descritivo-exploratório, integrante de uma pesquisa mais ampla $^{3}$, atento às movimentações de uma política municipal de Educação Especial, cuja operacionalização deu-se mediante análise documental da Resolução SEME n. 2/2017 e entrevista semiestruturada - a partir de um roteiro com 13 questões - com a representante da área na Secretaria Municipal de Educação de Maracaju. Neste texto, a participante será nominada como GMARA, sendo que as informações por ela fornecidas acompanham o ano da entrevista (2020).

Estruturalmente, os dados são apresentados em duas seções: a primeira elucida algumas influências externas presentes na interpretação municipal da Educação Especial, bem como descreve práticas locais empreendidas para o AEE; a segunda contempla a análise da normativa do município que disciplina a Educação Especial.

\section{Influências e práticas de Educação Especial em Maracaju}

Maracaju tem uma população de 37.405 habitantes e densidade demográfica de 7.06 $\mathrm{hab} / \mathrm{km}^{2}$ (IBGE, 2010). A rede municipal de ensino conta com 16 instituições escolares, sendo que oito delas dispõem de Salas de Recursos Multifuncionais (SRM) (GMARA, 2020). De acordo com o Censo Escolar, 224 alunos foram atendidos pela Educação Especial na rede municipal, no ano de 2019 (INEP, 2019). Além do atendimento em SRM, a rede municipal

${ }^{3}$ Submetida ao Comitê de Ética em Pesquisa Envolvendo Seres Humanos (CEP) da Universidade Federal da Grande Dourados, por meio da Plataforma Brasil, obtendo a Certificação de Apresentação para Apreciação Ética - CAAE 25876519.6.0000.5160.

RIAEE - Revista Ibero-Americana de Estudos em Educação, Araraquara, v. 16, n. esp. 2, p. 1360-1376, maio 2021. e-ISSN: 1982-5587 
oferece os seguintes serviços especializados: apoio em sala de aula comum, atendimento domiciliar e tradutor e intérprete de Libras (GMARA, 2020). O serviço de apoio em sala de aula é ofertado tanto por Professores de Apoio Pedagógico Especializado, quanto por Profissionais de Apoio Escolar, a depender da necessidade educacional apresentada pelo aluno.

A Gestora entrevistada (GMARA) assumiu a coordenação da Educação Especial de Maracaju em 2017. “Até então, nós não tínhamos nada organizado. Não tinha uma resolução, não tinha uma instrução normativa, não tinha nada" (GMARA, 2020). A falta de um documento normativo estava gerando muitos problemas. Existiam "muitos equívocos sobre o público-alvo da Educação Especial" e o seu encaminhamento aos atendimentos especializados ofertados pela rede municipal (GMARA, 2020). "Então, a primeira coisa que fizemos foi a resolução" (GMARA, 2020). Interessante mencionar que GMARA é servidora efetiva do quadro municipal e não recebe remuneração decorrente de cargo de confiança ou função gratificada na Gestão Municipal de Maracaju. Tal condição, segundo ela, lhe proporciona maior liberdade em sua atuação, tanto no lidar com os gestores municipais, a quem está subordinada, quanto na relação com os diretores das escolas: "eles confiaram no trabalho que está sendo desenvolvido. Mas, toda essa questão, desse olhar, sabe, de lutar, de querer, isso é uma coisa que não sai de mim mesmo. E eles me dão todo o apoio" (GMARA, 2020). Dentre as culturas profissionais que influenciam o processo de recontextualização política (BALL; MAGUIRE; BRAUN, 2016), Pavezi (2018) aponta a forma de condução aos cargos de liderança como um fator de modulação da atuação da política educacional em determinado contexto. Tal constatação é corroborada pelas falas de GMARA, que dão indícios de que a sua condição de certa independência de cargo político lhe confere maior autonomia na coordenação da Educação Especial em Maracaju.

Em 2017, a Secretaria Municipal de Educação elaborou a Resolução SEME n. 02/2017, com vistas a regulamentar os serviços da Educação da Especial. "A gente estudou muito para conhecer [a área], pesquisou outros lugares. Embora, aqui em Mato Grosso do Sul, nós tivemos muita dificuldade. [...] Então, eu trouxe muita coisa de São Paulo, de como era organizado lá, e de outros municípios" (GMARA, 2020). Percebe-se a influência da política atuada em outros contextos territoriais na construção da política de Educação Especial de Maracaju. Ball (apud MAINARDES, 2006) aponta que a era globalizada permite que a prática política em diferentes contextos, até mesmo internacionais, influencie a atuação das políticas educacionais, por meio do "empréstimo de políticas". Entretanto, ressalva que essas 
influências são sempre reinterpretadas e recontextualizadas à realidade local, num processo de "bricolagem" (BALL, 2001).

GMARA explicou que, antes da regulamentação, existiam muitas dúvidas quanto à atuação e à forma de contratação dos profissionais que atuam nos serviços de AEE: "Como funciona a carga horária do professor? O que ele tem que fazer? Ninguém sabia!" (GMARA, 2020). Neste cenário, a gestão da rede ensino municipal entendeu pela necessidade de se estabelecer uma política por meio de texto, considerando que "os textos políticos [...] representam a política. Essas representações podem tomar várias formas: textos legais oficiais e textos políticos, comentários formais ou informais sobre os textos oficiais, pronunciamentos oficiais, vídeos etc." (MAINARDES, 2006, p. 52). Assim, inicialmente, "a gente fez uma Instrução Normativa, que tinha basicamente o conteúdo da resolução [vigente], e encaminhou para todas as escolas" (GMARA, 2020). Posteriormente, por orientação da assessoria jurídica, se converteu o conteúdo da Instrução Normativa na Resolução SEME n. 02/2017. Neste documento, foram incluídos todos os serviços de AEE, para "ter subsídios para depois justificar o porquê [da contratação]" (GMARA, 2020). A partir dos critérios estabelecidos no documento, foi possível realizar, "no final de 2017, o primeiro processo seletivo para Professor de Apoio. Porque, antes, as contratações não eram mediante processo", ocorriam por meio de indicação política (GMARA, 2020). Dentre os critérios para contratação de Professor de Apoio, foi estabelecida a exigência de especialização em Educação Especial:

Até então, trabalhava na Educação Especial quem tinha a pós-graduação em Educação Especial, mas, também em Psicopedagogia, Neuropsicopedagogia, Neuropedagogia [...]; quem tinha curso, por exemplo, de 150 horas na Educação Especial. No processo seletivo, a gente coloca o que está estabelecido em lei: formação em Educação Especial. Pode ser com ênfase em altas habilidades, em deficiência intelectual, em autismo, mas tem que ser Educação Especial. [...] E formação de base em Pedagogia ou Normal Superior (GMARA, 2020).

No processo seletivo, ao menos na primeira remessa de contratação, não são aceitas especializações em outras áreas: se "dentre os aprovados tem gente que não tem a pós [específica], a gente desclassifica" (GMARA, 2020). Todavia, quando não são preenchidas todas as vagas para Professor de Apoio, "tem que fazer um novo chamamento [público]" (GMARA, 2020). Nessa segunda etapa, “abre para psicopedagogo, neuropsicopedagogo, para todos esses outros, porque a gente consegue suprir essa demanda inicial de acordo com o que estabelece em lei e, após isso, como faltaram profissionais formados, a gente consegue abrir [chamamento público]" (GMARA, 2020). 
De acordo com a Gestora, o critério para concessão dos serviços de AEE é a necessidade pedagógica identificada. A partir do momento em que o aluno chega à rede de ensino, mesmo "nos casos dos transtornos funcionais, como TDH, dislexia, disvalia, ainda que os alunos não sejam casos da Educação Especial, eles são únicos, como quaisquer outros, e têm direito de que o professor lhe faça adequação curricular" (GMARA, 2020). Entretanto, a entrevistada descreveu a resistência dos professores em superar os métodos tradicionais e ampliar as oportunidades de acessibilidade curricular. Neste sentido, os estudos de Costa e Denari (2014) demonstram que até mesmo a compreensão de adequação de curricular não é clara para muitos professores. Em decorrência desse processo de resistência, "a gente teve no ano passado uma aluna que a escola ficava o tempo todo: 'a mãe tem que trazer laudo, laudo, laudo'. Ela tinha dislexia e a mãe chegou com laudo de deficiência intelectual”. Ao indagar a mãe se acreditava naquele diagnóstico, esta respondeu: 'Não! Mas só assim vou ter Professor de Apoio, vou poder ajudar [minha filha], pois ela reprovou no ano passado"" (GMARA, 2020).

A solução encontrada pela gestão da rede ensino de Maracaju, para atendimento desses alunos com dificuldades de aprendizagem que não são PAEE, foi alocá-los "em uma sala onde eu sei que tem um professor para um aluno com deficiência” (GMARA, 2020). Para isso, "o ensalamento eu faço por aqui. Eu sei quem são esses alunos [com transtornos de aprendizagem] e sei com quem eu posso colocar" (GMARA, 2020). Ball (apud MAINARDES; MARCONDES, 2009) compreende a política como um processo criativo, rompendo com a ideia de que as políticas educacionais sejam meramente implementadas. $\mathrm{O}$ autor compara a política a uma peça teatral, em que a transposição do texto (político) para a prática envolve um processo de interpretação e criatividade. Tal processo ocorre de forma contextualizada, levando-se em conta, dentre outros fatores, os recursos humanos e materiais disponíveis (BALL, MAGUIRE, BRAUN, 2016). De modo que, "são criadas soluções no contexto, muitas vezes mais criativas do que a proposta oficial” (MAINARDES, 2017, p. 7).

Esta medida tem como fundamento a intenção da gestão da rede municipal de ensino para que haja um trabalho de colaboração em sala de aula, entre professor regente e o professor especialista em Educação Especial: "a gente vem tentando mostrar para eles que precisa trabalhar em bidocência" (GMARA, 2020). A ideia é que o Professor de Apoio atenda a classe e que não se crie uma dependência por parte do aluno PAEE, auxiliando, desta forma, o professor regente no desenvolvimento do conteúdo.

Os alunos que chegam à rede com laudo médico de deficiência passam por uma triagem quanto à necessidade ou não dos serviços de AEE ofertados. "Eu preciso ir lá avaliar, 
porque tem aluno que é danado mesmo, é indisciplinado, não é deficiência, não é um problema" (GMARA, 2020). Assim, adota-se o seguinte procedimento: "eu encaminho para sala de recursos; a professora faz avaliação pedagógica; a professora da sala e a coordenação pedagógica fazem todo esse acompanhamento; terminou isso, então eu vou" (GMARA, 2020). Geralmente, recebem serviço de Professor de Apoio os alunos com:

Deficiência intelectual, quando é muito grave, porque tem casos que não tem necessidade; os transtornos globais do desenvolvimento, o autismo. Todos eles, quando há necessidade. Não é porque chegou e tem o laudo, que [receberá serviço de apoio]. Até porque eu falo: "para que serve o laudo desses alunos, depois que vocês os têm na escola? Para pôr na gaveta! Porque vocês vão ter que buscar estratégias, assim como vocês teriam que buscar para qualquer outro" (GMARA, 2020).

De acordo com GMARA, os laudos médicos de deficiência não são acatados de forma acrítica. Sempre que possível, "eu costumo acompanhar. Os casos que são mais críticos, eu vou até o médico" (GMARA, 2020). Quando a gestão da rede ensino discorda do diagnóstico médico, contrapõe o profissional de Medicina.

A gente tem caso aqui de uma criança que chegou diagnosticada com autismo e eu fiz a avaliação. [...] Conversando com aquela família, falei: "tem alguma coisa errada nessa história". Comecei a perguntar sobre os momentos em que a criança ficava [irritada], os horários, e a encaminhei para uma nutricionista. A criança tinha uma alta intolerância à lactose e ao glúten. Aquelas manifestações de irritação sempre vinham após ingerir os alimentos. Ela chegou para a gente no segundo ano. Veja quanto tempo! Sete ou oito anos essa criança desse jeito e tinha um diagnóstico do neurologista de autismo. Foi feito todo o processo de reeducação alimentar e voltou para avaliação do neurologista e eu fui junto. Nem ele acreditou! (GMARA, 2020).

GMARA (2020) comentou que, "infelizmente, a gente vive numa sociedade que dá muita importância para a medicalização", que rotula precocemente crianças que não funcionam de acordo com o padrão de normalidade exigido. Para ela, "criança, até 10, 11 anos, é um crime diagnosticar com deficiência intelectual. Você tem ainda, entre os sete e oito anos, um pico de desenvolvimento muito grande. Parece que a criança vira a chave de uma hora para outra. E aí? E o diagnóstico que você deu?” (GMARA, 2020).

Em recente pesquisa realizada por Ribeiro (2020) nos municípios da região da Grande Dourados, de MS, quanto à caracterizações das matrículas de campesinos PAEE, constatouse, com base nos indicadores do Censo Escolar, que, no município de Maracaju, em 2018, $75 \%$ dos alunos campesinos PAEE matriculados em escolas rurais e $84,38 \%$ matriculados em escolas urbanas apresentavam deficiência intelectual. Em que pese os estudos de Ribeiro 
(2020) terem como objeto os estudantes campesinos, tais dados dão indícios de que, em Maracaju, a maioria dos alunos PAEE tem sido diagnosticada com deficiência intelectual, o que pode justificar a preocupação esboçada pela Gestora entrevistada.

Dentre os desafios para gestão da Educação Especial em Maracaju, GMARA aponta, no espectro das culturas profissionais (BALL; MAGUIRE; BRAUN, 2016), o estigma de especialização da responsabilidade pelo aluno PAEE, até mesmo nos setores administrativos da Secretaria Municipal de Educação, concentrando na coordenação responsável pela gestão da Educação Especial toda a responsabilidade pelas demandas desse alunado:

No próprio setor pedagógico da Secretaria, até hoje, existe uma resistência muito grande: "é teu aluno". Assim como acontece na escola: "aluno do Professor de Apoio", "aluno da sala de recursos". Nem a coordenação da escola quer saber desse aluno (GMARA, 2020).

A responsabilização unilateral de profissionais e professores da Educação Especial pela inclusão escolar de alunos PAEE tem sido recorrente em outros municípios sul-matogrossenses (NOZU, 2013; NOZU et al., 2020). Sob a frágil justificativa de não possuírem um saber especializado, muitos gestores e professores se eximem do compromisso de transformação das barreiras estruturais, didático-pedagógicas e atitudinais para a inclusão escolar, delegando-a aos profissionais/professores da Educação Especial (NOZU, 2013; NOZU; BRUNO, 2016).

Diante deste contexto, a rede municipal de ensino de Maracaju começou a investir em formações continuadas. "Começamos a trazer coordenação [pedagógica], professor regente e diretor [escolar] para formação em Educação Especial. Porque, a gente precisa fazer com que eles compreendam. Mas, ainda assim, é um caminho que a gente está engatinhando" (GMARA, 2020).

A partir de 2018, a rede de ensino instituiu o Plano Educacional Individualizado (PEI), "que é o plano de adequação curricular de todos os alunos que são atendidos pela Educação Especial" (GMARA, 2020), sendo que o ano de 2019 foi dedicado à formação dos profissionais para seu conhecimento e construção. O responsável pela elaboração é o Professor de Apoio, "mas ele tem que estar em contato com todos os professores daquele aluno: educação física, artes, se é séries finais, os das outras disciplinas, história, geografia, coordenação pedagógica e sala de recursos. Porque o trabalho deles precisa estar vinculado." (GMARA, 2020). Neste plano, deve conter: “a avaliação inicial desse aluno; o que ele já adquiriu de conceito para essa faixa etária e série; quais são as dificuldades; como eu vou adequar o currículo para trabalhar; quais são as atividades", além de "quando e como eu vou 
avaliar e o que eu vou propor de diferente para o próximo bimestre" (GMARA, 2020). A partir de sua instituição, o Professor de Apoio "precisa ir para sala de aula com material produzido" (GMARA, 2020). Para tanto, esses profissionais têm direito a "quatro horas atividades por semana, mas elas não têm horário fixo. São no melhor horário para o aluno" (GMARA, 2020).

GMARA mencionou que, em 2019, participou de um evento com vistas à reformulação da Política Nacional de Educação Especial. Demonstrou preocupação, pois, "a forma como ficou escrito dá interpretações diversas" (GMARA, 2020). A proposta dava margem para ampliação demasiada do PAEE. A preocupação da Gestora residia no fato que “a gente teve agora essa questão da redução do Fundeb, mas a demanda de alunos tem crescido. E é de alunos cada vez mais comprometidos. Essas crianças estão chegando com síndromes que a gente nunca viu" (GMARA, 2020). Essa realidade associada a uma possível expansão indiscriminada do PAEE poderia inviabilizar a prestação dos serviços de AEE a quem de fato necessita, por questões orçamentárias. A problematização da expansão indiscriminada dos serviços da Educação Especial é compartilhada por Mendes (2017). Segundo a autora, "há que se ter cuidado especial com os discursos que impliquem ampliar a cobertura, pois os já escassos recursos financeiros existentes poderão ser ainda mais diluídos, se forem destinados a todos os estudantes" (MENDES, 2017, p. 81), de modo que os alunos PAEE que de fato necessitam de serviços especializados poderão ter seu direito à escolarização negado sob justificativa orçamentária.

Relevante destacar que, em 30 de setembro de 2020, o Governo Federal publicou Decreto n. 10.502, que "institui a Política Nacional de Educação Especial: Equitativa, Inclusiva e com Aprendizado ao Longo da Vida". Embora este documento apresente alguns retrocessos no tocante ao direito à inclusão escolar, os quais não serão abordados nesse trabalho, o PAEE foi mantido como sendo os alunos com deficiência, transtornos globais do desenvolvimento (TGD) e altas habilidades/superdotação (BRASIL, 2020). Entretanto, no dia $1^{\circ}$ de dezembro de 2020, a eficácia do referido decreto foi suspensa por medida liminar expedida pelo ministro do Supremo Tribunal Federal Dias Toffoli, nos autos da Ação Direta de Inconstitucionalidade $n^{\circ}$ 6.590, ajuizada pelo Partido Socialista Brasileiro - PSB.

A Gestora demonstrou preocupação acerca do custeamento da Educação Especial: “agora eu estou compreendendo porque é que o estado já não está mais conseguindo colocar Professor de Apoio formado, começou a colocar profissional de nível médio. Porque a gente não aguenta pagar. E eu não sei até quando nós vamos conseguir" (GMARA, 2020). Considerou as implicações orçamentárias do crescimento da demanda por este serviço, 
"porque é uma demanda muito grande [...]. Eu fico pensando, assim, vai chegar a um ponto que não vai conseguir ter [professores especialistas] e vai ter que começar a brigar na justiça. Pois, nós não teremos [recursos]. Vai tirar dinheiro de onde para pagar?” (GMARA, 2020).

Tal fenômeno foi observado por Bezerra (2020) no município de Campo Grande, capital de MS, que, no ano de 2019, passou a substituir profissionais professores especialistas em Educação Especial, que atuavam no serviço de apoio em sala de aula comum, por profissionais com escolaridade em Ensino Médio completo. Aparentemente, trata-se de um processo de barateamento do serviço, considerando que a alteração ocorreu no meio do ano letivo, sem que fossem realizadas reavaliações dos alunos atendidos. Esse processo gerou forte resistência por parte dos pais de alunos PAEE e movimentos sociais, levando à judicialização do caso. $\mathrm{O}$ autor ainda apontou indícios de que o mesmo processo estivesse ocorrendo na rede estadual de ensino de MS (BEZERRA, 2020).

Com a diminuição na arrecadação de imposto durante a pandemia de Covid-19, o Governo Federal, por meio da Portaria Interministerial $n^{0} 3$, de 25 de novembro de 2020, reduziu em $8 \%$ o valor anual de investimento por aluno, o que pode tornar ainda mais desafiador o custeio dos serviços especializados, nas redes de ensino públicas.

\section{Produção textual da política municipal de Educação Especial: Resolução SEME n. 2/2017}

Os textos políticos, geralmente, são resultados da mediação de uma gama de ideologias e de interesses em disputa (MAINARDES, 2006). Desta forma, a análise do texto político "envolve a análise dos objetivos da política, os valores implícitos e explícitos, os silêncios (o que não é afirmado ou que é deixado de lado nos textos), bem como as ideias e conceitos explicitados" (MAINARDES; FERREIRA; TELLO, 2011, p. 159). Tendo isso em vista, nesta seção será analisada a Resolução SEME n. 2, de 26 de outubro de 2017, da Secretaria Municipal de Educação de Maracaju, que normatiza os serviços da Educação Especial em todas as etapas e modalidades da Educação Básica.

O documento referencia, expressamente, a consideração dos seguintes documentos nacionais para sua elaboração: Decreto Federal n. 7.611/2011, Lei Federal n. 13.146/2015 e Resolução CNE/CEB n. 04/2009; assim como as Deliberações CEE/MS n. 9.367/2010 e n. 7.828/2005, do Conselho Estadual de Educação (CEE/MS). Tais apontamentos dão indícios de que não apenas os textos políticos nacionais influenciaram a construção da política municipal de Educação Especial escrita em Maracaju, como também a política atuada nos 
normativos da rede estadual de ensino, visto a expressa referência às deliberações do CEE/MS (MARACAJU, 2017), demonstrando, mais uma vez, o processo criativo de "empréstimo de política" (MAINARDES, 2006).

O Capítulo II do documento é destinado a regulamentar o AEE, ali conceituado como "conjunto de atividades, recursos de acessibilidade e pedagógicos organizados institucionalmente, prestado de forma complementar ou suplementar à formação do estudante no ensino comum" (MARACAJU, 2017, Art. $8^{\circ}$ ). Da leitura deste capítulo, nota-se que o AEE é entendido como o conjunto de serviços ofertados extraclasse, com ênfase nos atendimentos prestados em SRM e Centros de Atendimento Educacional Especializados públicos ou de instituições privadas sem fins lucrativos. O Art. 11 dispõe que o professor atuante no AEE em SRM deve ter graduação em curso de licenciatura e especialização lato sensu em Educação Especial.

GMARA informou que, nos Centros Integrados de Educação Infantil (CIEI), não há SRM fixas, "é como se elas fossem itinerantes. Então, o professor da sala de recursos da escola vai até a creche, para avaliar a criança lá, e, quando precisa, chama a família na escola" (GMARA, 2020). Entretanto, a Resolução SEME n. 2/2017 é silente quanto a essa sistemática de atendimento na Educação Infantil. Neste ponto, Bruno e Nozu (2019) observam que, embora o governo brasileiro tenha instituído Diretrizes Operacionais para o AEE na Educação Básica, "no contexto da prática, essas ações foram implementadas, predominantemente, no âmbito do Ensino Fundamental, sendo que na Educação Infantil ainda imperam inúmeras dúvidas quanto à oferta e a operacionalização do AEE” (BRUNO; NOZU, 2019, p. 691).

O Capítulo III se destina a disciplinar o serviço do Professor de Apoio Pedagógico Especializado, enquanto o Capítulo IV disciplina o serviço do Profissional de Apoio Escolar. Esses são serviços ofertados dentro das salas de aula, mas que se optou por regulamentá-los em capítulos distintos, isto é, de forma apartada. Ao que parece, há a intenção de demarcar a natureza de cada um desses serviços e os limites das atribuições dos profissionais neles atuantes (MARACAJU, 2017). Os Arts. 24 e 29 preveem que a contratação desses profissionais "poderá" ocorrer mediante processo seletivo. Vê-se que, no documento, destoando da fala de GMARA, a contratação por meio de processo seletivo é tida como uma possibilidade, não como a regra.

A Resolução prevê que o Professor de Apoio Pedagógico Especializado pode atuar tanto no Ensino Fundamental, quanto na Educação Infantil (MARACAJU, 2017, Art. 20). Para tanto, dever ter especialização em Educação Especial, sendo que, para atuar na Educação Infantil e nos anos iniciais do Ensino Fundamental, a formação de base deve ser em 
Pedagogia; enquanto para atuar nos anos finais do Ensino Fundamental, a formação pode ser em Pedagogia e/ou nas áreas de Ciências Humanas e Exatas (MARACAJU, 2017, Art. 23).

No rol de atribuições do Professor de Apoio, previsto no Art. 22, estão funções como de: adequação das atividades didático-pedagógicas e disponibilização de recursos de acessibilidade; atuação de forma colaborativa com professor regente, no sistema de bidocência; identificação, elaboração, produção e organização de estratégias e recursos pedagógicos de acessibilidade; elaboração e execução do PEI; promoção da socialização do estudante; auxílio nas atividades de higiene, alimentação e mobilidade dentro do contexto escolar (MARACAJU, 2017). Nota-se que há ênfase na atuação colaborativa entre professor regente e professor especialista, intencionando uma relação de bidocência. Segundo Mendes e Malheiro (2012), o trabalho colaborativo emergiu como uma estratégia que visa levar os recursos necessários ao AEE do aluno PAEE para a classe comum, de modo a se evitar a sua retirada do contexto de sala de aula, subvertendo a lógica dos modelos de sala de recursos, classes especiais ou escolas especiais.

O Profissional de Apoio Escolar atende aos alunos que necessitam de apoio nas atividades de higiene, alimentação e transporte (Art.26), não lhe competindo qualquer atividade educativa diferenciada (Art. 26, parágrafo único). De acordo com o Art. 27 da resolução, para atuar nessa função o profissional deve ter, no mínimo, 18 anos, ter o Ensino Médio completo e participar das formações e capacitações ofertadas pela Secretaria Municipal de Educação (MARACAJU, 2017).

Percebe-se que o documento conferiu funções pedagógicas somente ao Professor de Apoio, todavia, as atividades de suporte à alimentação, locomoção e higiene, quando necessárias, são comuns aos dois profissionais. A figura do Professor de Apoio Pedagógico Especializado se assemelha ao professor especialista previsto na Resolução CNE/CEB n. 02/2001 para prestar Apoio Pedagógico Especializado na sala de aula comum, aos alunos PAEE (BRASIL, 2001); enquanto o Profissional de Apoio Escolar previsto no normativo municipal, aparentemente, é uma reprodução do personagem previsto na Lei n. 13.146/2015, visto que as funções são as mesmas ali dispostas (BRASIL, 2015).

A Resolução CNE/CEB n. 02/2001 apresenta, no conjunto de serviços denominado Apoio Pedagógico Especializado, um professor especializado atuando em sala de aula comum para apoiar o aluno PAEE, quando necessário (BRASIL, 2001). Entretanto, esse serviço tem recebido pouca atenção nos textos políticos subsequentes, ao passo que a preferência pelo atendimento nas SRM tem ganhado centralidade nas proposições políticas (NOZU, 2013). Desde 2001, o serviço de apoio em sala de aula comum vem se reconfigurando nos 
documentos político-normativos, a partir de poucas e vagas disposições, de modo que suas funções pedagógicas e específicas foram se perdendo, nesses documentos, assemelhando-se mais a um serviço de cuidado/monitoria, não restando claro se a política nacional intencionou a substituição do professor especializado por um cuidador sem formação específica, ou a coexistência dos dois personagens, o que tem possibilitado diversas (re)interpretações desse serviço nas redes de ensino brasileiras (MARTINS, 2011). Da análise da Resolução SEME n. 2/2017, há indícios de que, na rede de ensino municipal de Maracaju, a interpretação da política nacional de Educação Especial é pela coexistência dos dois personagens, com funções e formação distintas e delimitadas (MARACAJU, 2017).

O Art. 21, da Resolução SEME n. 2/2017, elegeu como público-alvo do serviço de Professor de Apoio Pedagógico os alunos "com deficiência física/neuromotora severa, associada ou não a outra deficiência”, e os alunos:

[...] com transtorno global do desenvolvimento, em casos de comprovada necessidade, que apresentem deficiência persistente e clinicamente significativa de comunicação e de interação social, manifestada por deficiência marcada de comunicação verbal e não verbal usada para interação social; ausência de reciprocidade social; ausência significativa de capacidade em desenvolver e manter relações apropriadas ao seu nível de desenvolvimento (MARACAJU, 2017, Art. 21)

Nota-se que, no documento, o público-eleito para o atendimento de Professor de Apoio é constituído ora pelo tipo de deficiência diagnosticada, ora pela comprovação da necessidade educacional. Já o Profissional de Apoio Escolar tem como público os alunos que necessitam de suporte às ações de alimentação, higiene e locomoção. No mesmo sentido, ao disciplinar a organização do AEE, o inciso VII, do Art. 13, dispõe sobre a transitoriedade desse atendimento, que deve ocorrer pelo tempo necessário para a superação das barreiras que impedem a plena participação educacional do estudante, buscando-se sempre a sua autonomia no ambiente escolar (MARACAJU, 2017). Desta forma, o texto oscila entre disposições que vinculam os serviços especializados à condição clínica de deficiência e disposições que preveem a avaliação da necessidade específica do aluno.

\section{Considerações finais}

O processo de municipalização da educação tem confrontado os municípios brasileiros a prover e estruturar os apoios especializados necessários à consecução das políticas de inclusão escolar. Diante das demandas do cotidiano da prática educacional, muitas vezes 
surge, também, a necessidade de regulamentar a oferta desses atendimentos, considerando as limitações orçamentárias.

No município de Maracaju, a Educação Especial foi regulamentada pela Resolução SEME n. 2/2017. A necessidade de um documento político-normativo foi identificada pela gestão da rede de ensino principalmente pela inexistência de critérios para contratação de Professores de Apoio para atuar no AEE, o que estava sobrecarregando a folha de pagamento do município.

Dentre as principais dificuldades apontadas na condução da política de Educação Especial estão as culturas profissionais de responsabilização dos agentes que atuam na Educação Especial por todas as demandas que envolvam os alunos PAEE, ignorando-se que, antes de serem público da Educação Especial, são alunos da rede de ensino. Ainda, registrouse a resistência intra rede de ensino em ofertar respostas educativas diferenciadas às necessidades dos estudantes, sem vinculá-las à apresentação de laudos médicos. Nesse sentido, a Gestora problematizou a produção social da deficiência, mediante diagnósticos médicos emitidos de forma precoce, sem que haja acompanhamento e avaliação ampla da criança.

Embora nas falas de GMARA haja indícios de uma compreensão biopsicossocial da deficiência, na Resolução SEME n. 2/2017 há disposições que sinalizam uma abordagem clínica, em que a deficiência diagnosticada é o critério para a concessão do serviço especializado. Quanto ao serviço de apoio em sala de aula comum, a rede municipal de Maracaju tem priorizado Professores de Apoio com especialização em Educação Especial, sendo admitidos Profissionais de Apoio Escolar, com Ensino Médio, somente quando a assistência se restringe ao auxílio nas atividades de higiene, locomoção e alimentação. Entretanto, com a diminuição dos recursos do Fundeb e a crescente quantidade de alunos com deficiência, há preocupação por parte da gestão da rede de ensino quanto à possibilidade de que, em um futuro próximo, o custeio de professores especialistas seja inviabilizado e se incorra em movimento semelhante ao observado na rede municipal da capital do estado, bem como na rede estadual de MS, de substituição de professores especialistas em Educação Especial por profissionais com apenas Ensino Médio.

Diante da crise econômica decorrente da pandemia de Covid-19, o repasse do Fundeb para 2020 foi ainda mais reduzido, de modo que os desafios orçamentários impostos aos gestores das redes de ensino para custeamento dos serviços de AEE, provavelmente, serão ainda maiores, o que pode desencadear um processo de barateamento de mão de obra e precarização dos serviços da Educação Especial. 


\section{REFERÊNCIAS}

BALL, S. J. Diretrizes políticas globais e relações políticas locais em educação. Currículo sem Fronteiras, v. 1, n. 2, p. 99-116, jul./dez. 2001.

BALL, S. J.; MAGUIRE, M.; BRAUN, A. Como as escolas fazem as políticas: atuação em escolas secundárias. Ponta Grossa: Editora UEPG, 2016.

BEZERRA, G. F. O Apoio Pedagógico Especializado em classe comum: o caso de Campo Grande - MS como metonímia da precarização na educação especial. LES: Ling. Educ. Socie, Teresina, ano 25, n. 44, jan./abr. 2020.

BRASIL. Resolução n. 2, de 11 de setembro de 2001. Brasília, DF: CNE. CEB, 2001.

BRASIL. Constituição da República Federativa do Brasil (1988). Brasília: Congresso Nacional, 1988.

BRASIL. Decreto n. 10.502, de 30 de setembro de 2020. Institui a Política Nacional de Educação Especial: Equitativa, Inclusiva e com Aprendizado ao Longo da Vida. Brasília, DF, 01 out. 2020. Diário Oficial da União: Seção 1, Brasília, DF, p. 6, 01 out. 2020.

BRASIL. Lei n. 9.394, de 20 de dezembro de 1996. Lei de Diretrizes e Bases da Educação Nacional. Diário Oficial da União: Seção 1, Brasília, DF, n. 248, p. 27833, 23 dez. 1996. PL $1258 / 1988$

BRASIL. Política Nacional de Educação Especial na Perspectiva da Educação Inclusiva. Brasília, DF: MEC. SEESP, 2008.

BRASIL. Portaria Interministerial n. 3, de 25 de novembro de 2020. Altera parâmetros operacionais do Fundo de Manutenção e Desenvolvimento da Educação Básica e de Valorização dos Profissionais da Educação - Fundeb, para o exercício de 2020. Diário Oficial da União: Seção 1, Brasília, DF, p. 1, 26 nov. 2020.

BRASIL. Lei n. 13.146, de 06 de julho de 2015. Institui a Lei Brasileira de Inclusão da Pessoa com Deficiência (Estatuto da Pessoa com Deficiência). Diário Oficial da União: Seção 1, Brasília, DF, p. 2, 07 jul. 2015. PL 7699/2006

BRUNO, M. M. G.; NOZU, W. C. S. Política de inclusão na Educação Infantil: avanços, limites e desafios. Revista Ibero-Americana de Estudos em Educação, Araraquara, v. 14, n. esp. 1, p. 686-701, abr. 2019. DOI: https://doi.org/10.21723/riaee.v14iesp.1.12199

COSTA, V. B.; DENARI, F. E. Concepção docente sobre adequação curricular na educação inclusiva. Revista Ibero-Americana de Estudos em Educação, Araraquara, v. 9, n. 1, p. 27 34, 2014. DOI: https://doi.org/10.21723/riaee.v9i1.6854

FOUCAULT, M. Vigiar e punir: nascimento da prisão. Petrópolis: Vozes, 2010.

GARCIA, R. M. C. Política de educação inclusiva e trabalho pedagógico: uma análise do modelo de educação especial na educação básica. In: BAPTISTA, C. R.; JESUS, D. M. 
Avanços em políticas de inclusão: o contexto da educação especial no Brasil e em outros países. Porto Alegre: Mediação/CDV/FACITEC, 2009. p. 123-138.

GARCIA, R. M. C. Políticas inclusivas na educação: do global ao local. In: BAPTISTA, C. R.; CAIADO, K. R. M.; JESUS, D. M. Educação especial: diálogo e pluralidade. 2. ed. Porto Alegre: Mediação, 2010. p. 11-23.

IBGE. Cidades. Disponível em: https://cidades.ibge.gov.br/. Acesso em: 24 ago. 2020.

MAINARDES, J. A abordagem do ciclo de políticas: explorando alguns desafios da sua utilização no campo da Política Educacional. Jornal de Políticas Educacionais, v. 12, n. 16, ago. 2018.

MAINARDES, J. Abordagem do Ciclo de Políticas: uma contribuição para a análise de políticas educacionais. Educ. Soc., Campinas, v. 27, n. 94, p. 47-69, jan./abr. 2006.

MAINARDES, J. Alguns desafios em trabalhar com a abordagem do ciclo de políticas. (Working paper). 2017. Disponível em:

https://www.researchgate.net/profile/Jefferson_Mainardes. Acesso em: 18 out. 2020.

MAINARDE, J.; FERREIRA, M. S.; TELLO, C. Análise de políticas: fundamentos e principais debates teórico-metodológicos. In: BALL, S. J.; MAINARDES, J. (Org.). Políticas Educacionais: questões e dilemas. São Paulo, Cortez, 2011. p. 143-172.

MAINARDES, J.; MARCONDES, M. I. Entrevista com Stephen J. Ball: um diálogo sobre justiça social, pesquisa e política educacional. Educ. Soc., Campinas, v. 30, n. 106, p. $303-$ 318, jan./abr. 2009.

MARACAJU. Resolução SEME n. 002, de 26 de outubro de 2017. Maracaju, MS, 2017.

MARTINS, S. M. O profissional de apoio na rede regular de ensino: a precarização do trabalho com os alunos da Educação Especial. 2011. 168 f. Dissertação (Mestrado em Educação) - Universidade Federal de Santa Catarina, Florianópolis, 2011.

MENDES, E. G. Sobre alunos "incluídos" ou "da inclusão": reflexões sobre o conceito de inclusão escolar. In: VICTOR, S. L.; VIEIRA, A. B.; OLIVEIRA, I. M. (Org.). Educação especial inclusiva: conceituações, medicalização e políticas. Campos dos Goytacazes, RJ: Brasil Multicultural, 2017. p. 60-83.

MENDES, E. G.; MALHEIRO, C. A. Lima. Salas de recursos multifuncionais: é possível um serviço "tamanho único" de atendimento educacional especializado? In: MIRANDA, T. G.; GALVÃO FILHO, T. (Org.). O professor e a educação inclusiva: formação, práticas e lugares. Salvador: EDUFBA, 2012. p. 349-366.

NOZU, W. C. S. Política e gestão do atendimento educacional especializado nas salas de recursos multifuncionais de Paranaíba/MS: uma análise das práticas discursivas e não discursivas. 2013. 241 f. Dissertação (Mestrado em Educação) - Universidade Federal da Grande Dourados, Dourados, 2013. 
NOZU, W. C. S.; BRUNO, M. M. G. Formação de professores em tempos de inclusão: estratégia para o governo de si e dos outros. In: MARQUES, E. P. S.; GOMES FILHO, M. (Org.). Educação, diversidade e inclusão: os desafios para a docência. Campo Grande: Life, 2016. p. 181-194.

NOZU, W. C. S. et al. Inclusão de alunos da Educação Especial em escola do campo: possibilidades de um trabalho colaborativo? Rev. Bras. Educ. Camp., Tocantinópolis, v. 5, e8972, 2020.

PAVEZI, M. Políticas de Educação Especial no Estado de Alagoas. 2018. 218 f. Tese (Doutorado em Educação - Área de Contração: Educação) - Universidade Estadual de Ponta Grossa, Ponta Grossa, 2018.

RIBEIRO, E. A. Inclusão de camponeses público-alvo da educação especial em escolas da região da Grande Dourados. 2020. Dissertação (Mestrado em Fronteiras e Direitos Humanos) - Universidade Federal da Grande Dourados, Dourados, 2020.

\section{Como referenciar este artigo}

AGRELOS, C. S. T.; NOZU, W. C. S. (Con)textualização da política de educação especial em um município sul-mato-grossense. Revista Ibero-Americana de Estudos em Educação, v. 16, n. esp. 2, p. 1360-1376, maio 2021. e-ISSN: 1982-5587. DOI: https://doi.org/10.21723/riaee.v16iesp2.15130

Submissão em: $15 / 12 / 2020$

Revisões requeridas em: 28/01/2021

Aprovado em: 03/03/2021

Publicado em: 01/05/2021 